Original Research Paper

\title{
Development of a Hybrid Power Module for Mobile Wireless Sensor Networks: Towards a Livestock Tracking and Identification System
}

\author{
Obakeng Maphane, Oduetse Matsebe and Molaletsa Namoshe \\ Department of Mechanical, Energy \& Industrial Engineering, \\ Faculty of Engineering \& Technology, Private Bag BO 016, Palapye, Botswana
}

Article history

Received: 29-06-2017

Revised: 13-07-2017

Accepted: 6-10-2017

Corresponding Author: Oduetse Matsebe Department of Mechanical, Energy \& Industrial Engineering, Faculty of Engineering \& Technology, Botswana International University of Science and Technology, Private Bag BO 016, Palapye, Botswana Email: matsebeo@biust.ac.bw

\begin{abstract}
Smart technology and Internet of Things (IoT) applications have gained popularity in the development of agricultural systems with Wireless Sensor Networks (WSNs) increasingly becoming the building blocks for IoT applications. However, WSNs have a limited power supply. As a result, these systems have a short lifespan, limited memory and low computing power. This paper describes the development of a hybrid power module for WSN to be utilized in a livestock tracking and identification system. Mathematical and MATLAB-Simulink models are developed and used to simulate the characteristics of a lithium ion (Liion) battery; to power the mobile sensor node (eartag), a nickel metal hydrate $(\mathrm{NimH})$ battery used to power the static sensor nodes, a solar cell and the hybrid power module. Simulation results show that individually, the power sources provide limited power but the hybrid system coupled with a switching block generates enough power for the system, this implies that the system is viable but a prolonged operation of the system will depend on the battery limitations and climatic conditions. Future work will focus on the development of a prototype that can be tested and validated in real environment.
\end{abstract}

Keywords: Solar Power, Hybrid Energy, Internet of Things, Wireless Sensor Networks

\section{Introduction}

The application of mobile WSN in remote areas is limited by factors such as power sources, size of nodes and the inaccessibility of nodes for longer periods of time. Hybrid power systems using renewable energy sources can prolong the power needs for many applications in energy scarce environments. The projected increase of Photovoltaic (PV) applications and advances in thin-film solar cells technology provides many opportunities for application of solar on wearable devices and in small surface areas (Jager et al., 2014). A lot of research has been done on application of PV technology on WSN and on the application of WSN to tracking (Raizma et al., 2013), (Foulkes et al., 2013), (Huircan et al., 2010), (Kwong et al., 2012), (Nagl et al., 2003), (Choi et al., 2013). Due to the explosion of IoT research and smart technologies, WSN applications have increased significantly. It is inevitable that smart technology be applied on agriculture for nations that depends on agro-business. This paper describes the development of a hybrid power module for WSN to be utilised in a livestock tracking and identification system. Mathematical and MATLAB-Simulink models are developed and used to simulate the characteristics of a lithium ion (Li-ion) battery used to power the mobile sensor node (ear tag), a nickel metal hydrate (NimH) battery used to power the static sensor nodes, a solar cell and the hybrid power module which comprises off Li-ion batteries and solar cells or NimH batteries and solar panel. The rest of the paper is structured as follows: Section 2 gives a review of related literature works, Section 3 outlines the mathematical and MATLAB-Simulink models used for the power sources, Section 4 presents the simulation results, Section 5 provides a discussion of the results, Sections 6 and 7 respectively presents the conclusion and further work. 


\section{Literature review}

A lot of research has been done in application of WSN, power optimization of WSN nodes and livestock tracking or farm management using WSN.WSNs have been applied to solve monitoring and localization problems. Researchers in (Huircan et al., 2010), developed a cattle localization and monitoring system based on ZigBee protocol using Link Quality Indicator (LQI) coupled with a modified Ratio metric vector Iterations (RVI) routing algorithm for ranging or distance calculation. An estimation and localization algorithm is used as opposed to a Global Positioning Satellite (GPS) which is a more precise method but expensive for livestock applications. A link of static anchors attached to poles and mobile sensors attached to cattle ear tags encased in plastic casing are used. The system is powered by lithium ion battery while anchor nodes are solar powered. Detection ranges of $200 \mathrm{~m}$ in the laband $220 \mathrm{~m}$ in the field are reported in this work.

Research work by (Nagl et al., 2003) and (Foulkes et al., 2013), developed a system for remote monitoring of state of health for cattle using sensor network and Bluetooth as gateway or base station for telemetry and WSN respectively. Bluetooth is a power hungry tool, short range and depends on line of sight communication protocol, therefore it is affected by interference with other animals and trees. However, researchers in (Foulkes et al., 2013) deployed ear tags attached to cattle using solar cells and rechargeable batteries for prolonged life span of the WSN.

Authors in (Kwong et al., 2009), focused on the adaptation of WSN application on dairy farming and for an enclosed area. The researchers developed a low cost, low power consumption sensor node, for real time communication based on channel bandwidth and radio frequency. Various frequencies from $315 \mathrm{MHz}$ to 2.4 $\mathrm{GHz}$ are considered and their penetration depths. The main challenge in adapting wireless sensor networks is reported to be the support for nodes mobility caused by animal movements. A multi-hop routing protocol is reported to be better than store and forward in farming application and that GSM based tracking is expensive.

Authors in (Kwong et al., 2012), investigated the practicality of WSN in cattle monitoring applications, the work defines deployment challenges, wireless framework issues, design consideration, analysis of animal mobility, data collection, real time collection and simulations. Animal-movements are reported to be a major challenge in downloading capability. However, authors in (Choi et al., 2013), designed a cluster based routing protocol and architecture for tracking livestock in Mongolia focus on scalability, mobility and energy efficiency. The work identifies large herds of livestock and vast pastureland livestock herding as a challenge in open ranges and application of WSN is limited by scalability and energy efficiency, hence a clustering algorithm is used for the architecture and the nodes are subdivided by the introduction of mobile sinks through GSM network. Cluster based routing protocols; LEACHMobile Enhanced and Mobile Sink based Routing Protocol (MSRP) based on the remoteness mobility metric are used. The work postulates that after deployment, the algorithm and architecture should assist in providing economic status of livestock census and tracking, improve quality if pasture due to improved management schemes and disease prevention and control from health monitoring systems. This work develops a hybrid power module for WSN to be utilised in a livestock tracking and identification system. The hybrid system coupled with a switching block generates enough power for the system.

\section{Methodology}

This section describes the mathematical and MATLAB - Simulink models used to simulate the development of a hybrid power system. The mathematical model of the $\mathrm{Li}$-ion batteries used for a Simulink block are shown in Equations 1 and 2, showing discharge and charge models. Equations 3 and 4 show the model of the NimH batteries to used in the static nodes, models of thin film solar cell also used to create block diagram for the solar power modules are shown in Equations 5 and 6.

\section{Lithium Ion Battery (Li-ion) Model}

Lithium ion batteries are used to power mobile sensor nodes because of their light weight and compactness. Equations 1 and 2 respectively show the discharge and charging models of the Li-ion battery as explained in (Tremblay and Dessaint, 2009).

Li-ion discharge with $\mathrm{i}^{*}>0$ :

$$
f_{1}\left(i_{t}, i^{*}, i\right)=E_{0}-K \cdot \frac{Q}{Q-i_{t}} \cdot i^{*}-K \cdot \frac{Q}{Q-i_{t}} \cdot i_{t}+A \cdot e^{\left(-B \cdot i_{t}\right)}
$$

Li-ion charge with $i^{*}<0$ :

$$
f_{2}\left(i_{t}, i^{*}, i\right)=E_{0}-K \cdot \frac{Q}{0.1 . Q+i_{t}} \cdot i^{*}-K \cdot \frac{Q}{Q-i_{t}} \cdot i_{t}+A \cdot e^{\left(-B \cdot i_{t}\right)}
$$

Where:

$E_{0} \quad$ - Constant voltage $(V)$

$\operatorname{Exp}(s)$ - exponential zone dynamics $(V)$

$K$ - Polarization constant $\left(A h^{-1}\right)$ (Ohms)

$i^{*} \quad$ - Low frequency current dynamics $(A)$

$i$ - Battery current $(A)$

$i_{t} \quad$ - Extracted capacity $(A h)$

$Q \quad$ - Maximum battery capacity $(A h)$

$A \quad$ - Exponential voltage $(V)$

$B \quad$ - Exponential capacity $(A h)^{-1}$

Mobile sensor nodes use a $5 \mathrm{~V}$ battery pack made up of a combination of coin cell batteries, Fig. 1 shows the Simulink model used to simulate the Li-ion batteries. 


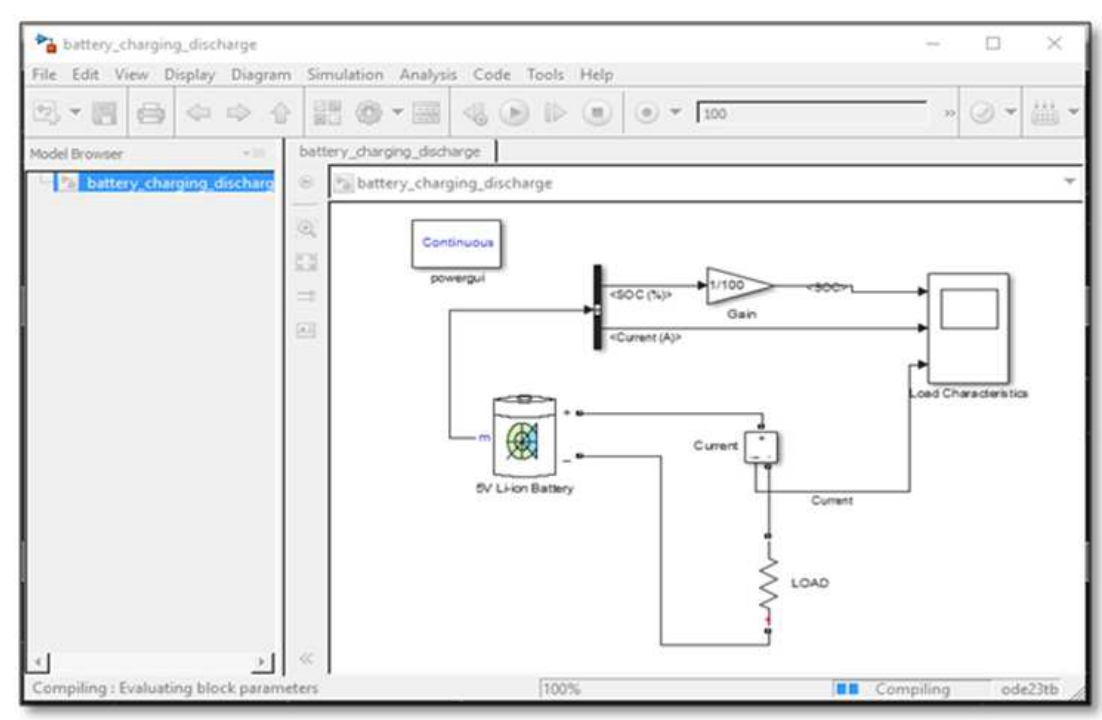

Fig. 1. Li-ion 5V Simulink model

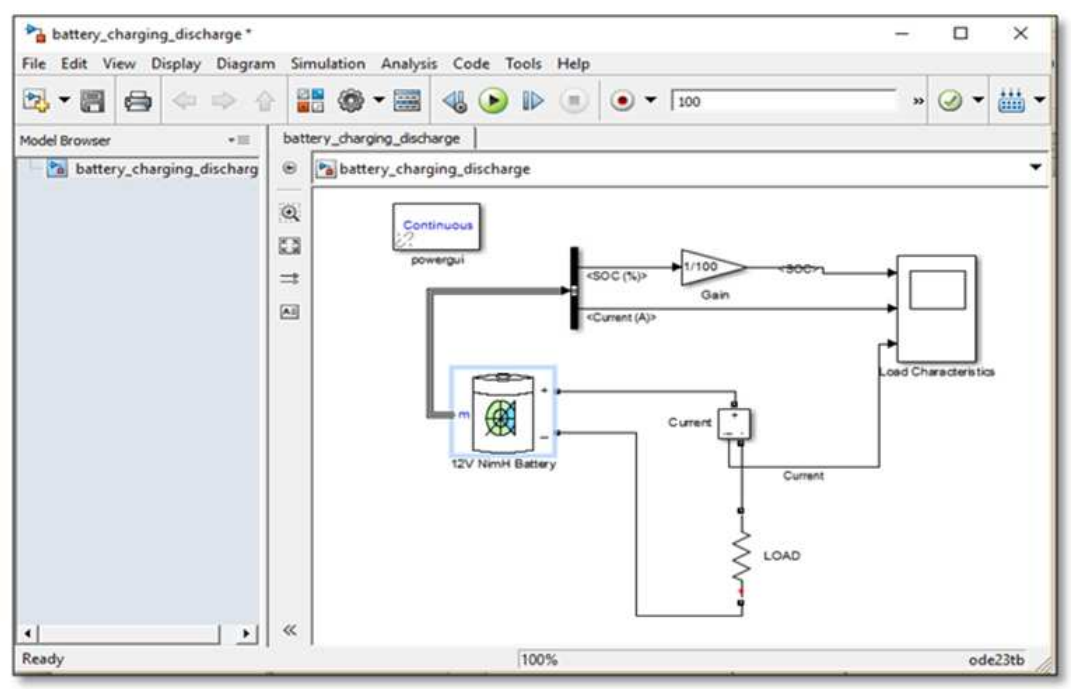

Fig. 2. NimH 12V Simulink model

The load resistor represents the total component requirements for the ear tag device. The battery must provide enough energy for at least half of the day when there is no sunlight and when solar is not producing enough to power.

Static sensor nodes use $12 \mathrm{~V}$ NimH batteries. Equations 3 and 4 respectively describe the discharge and charge models of the NimH battery in (Tremblay and Dessaint, 2009).

NimH discharge model with $i^{*}>0$ :

$f_{1}\left(i_{t}, i^{*}, i, \operatorname{Exp}\right)=\left[\begin{array}{c}E_{0}-K \cdot \frac{Q}{Q-i_{t}}, i^{*}-K \cdot \frac{Q}{Q-i_{t}} \cdot i_{t} \\ +\operatorname{Laplace}^{-1}\left(\frac{\operatorname{Exp}(s)}{\operatorname{Sel}(s)}\right)\end{array}\right]$
NimH charge model with $i^{*}<0$ :

$$
f_{2}\left(i_{t}, i^{*}, i, \operatorname{Exp}\right)=\left[\begin{array}{c}
E_{0}-K\left(\frac{Q}{\left|i_{t}\right|+0.1^{*} Q}\right) \cdot i^{*}-K\left(\frac{Q}{Q-i_{t}}\right) i_{t} \\
+ \text { Laplace }^{-1}\left(\frac{\operatorname{Exp}(s)}{\operatorname{Sel}(s)} \cdot \frac{1}{S}\right)
\end{array}\right]
$$

Where:

$E_{0} \quad$ - Constant voltage (V)

$\operatorname{Exp}(s)$ - exponential zone dynamics (V)

$\operatorname{Sel}(s)$ - Represents the battery mode; $\operatorname{Sel}(s)=0$ during battery discharge, Sel $(1)=1$ during battery charging.
$K$ - Polarization constant $\left(A h^{-1}\right)$ or Polarization resistance (Ohms)




$$
\begin{array}{ll}
i^{*} & \text { - Low frequency current dynamics }(A) \\
i & \text { - Battery current }(A) \\
i_{t} & \text { - Extracted capacity }(A h) \\
Q & \text { - Maximum battery capacity }(A h)
\end{array}
$$

Static sensor nodes use a $12 \mathrm{~V}$ battery pack. Fig. 2 shows the Simulink model used to simulate $\mathrm{NimH}$ batteries. The load resistor represents the total component requirements for the static sensor node.

\section{Solar Cell Model}

A solar cell representation based on current generated by exposure to solar irradiance is used. Equations 5 and 6 respectively describe mathematical representations of solar output current and solar induced current for a solar cell (Gow and Manning, 1999).

Solar output Current:

$$
I=\left[I_{p h}-I_{s}\left(e^{\left(\frac{V+I R_{s}}{N V_{t}}\right)}-1\right)-I_{s 2}\left(e^{\left(\frac{V+I R_{s}}{N_{2} V_{t}}\right)}-1\right)-\left(\frac{V+I R_{s}}{R_{p}}\right)\right]
$$

Solar induced current:

$$
I_{p h}=I_{p h o}\left(\frac{I_{r}}{I_{r 0}}\right)
$$

Where:

$I_{r}$ - irradiance (light intensity) in $\mathrm{W} / \mathrm{m}^{2}$ falling on the cell

$I_{p h 0}$ - measured solar-generated current for the irradiance $I_{r 0}$

$I_{s}$ - saturation current of the first diode

$I_{s 2}$ - saturation current of the second diode

$N$ - Quality factor (diode emission coefficient) of the first diode

$N_{2}$ - quality factor (diode emission coefficient) of the second diode

$V$ - Voltage across the solar cell electrical ports

$V t$ - thermal voltage, $\mathrm{kT} / \mathrm{q}$. where

$k$ - Boltzmann constant

$T$ - Device simulation temperature parameter value

$q$ - Elementary charge on an electron

Table 1 shows the parameters used to configure the solar cell component, the series connected cells are simulated at an assumed irradiance of $1000 \mathrm{~W} / \mathrm{m}^{2}$ and a constant temperature of $25^{\circ} \mathrm{C}$.

Based on the solar cell component defined in equations 5 and 6 , a stack is created by combining four solar cells generating 0.6 Voc. The series connected solar cells in Fig. 3 are used to create a PV array subsystem shown in Fig. 4. The sub-system is used to create different solar capacities.

Table 1: Single solar cell parameter

\begin{tabular}{ll}
\hline Parameter & Value \\
\hline Short-circuit current $[A]$ & $I_{s c}=7.34$ \\
Open-Circuit current $[\mathrm{V}]$ & $V_{o c}=0.6$ \\
Quality factor & $N=1.5$ \\
Series resistance $[\Omega]$ & $R_{s}=0$ \\
First order temperature coefficient for $I_{p h}[1 / K]$ & $T I P H 1=0$ \\
Temperature exponent for $I_{s}$ & $T X I S 1=3$ \\
Temperature exponent for $R_{s}$ & $T R S 1=0$ \\
Parameter extraction temperature $\left[{ }^{\circ} \mathrm{C}\right]$ & $T$ \\
Fixed circuit temperature $\left[{ }^{\circ} \mathrm{C}\right]$ & $T_{\text {meas }}=25$ \\
\hline
\end{tabular}

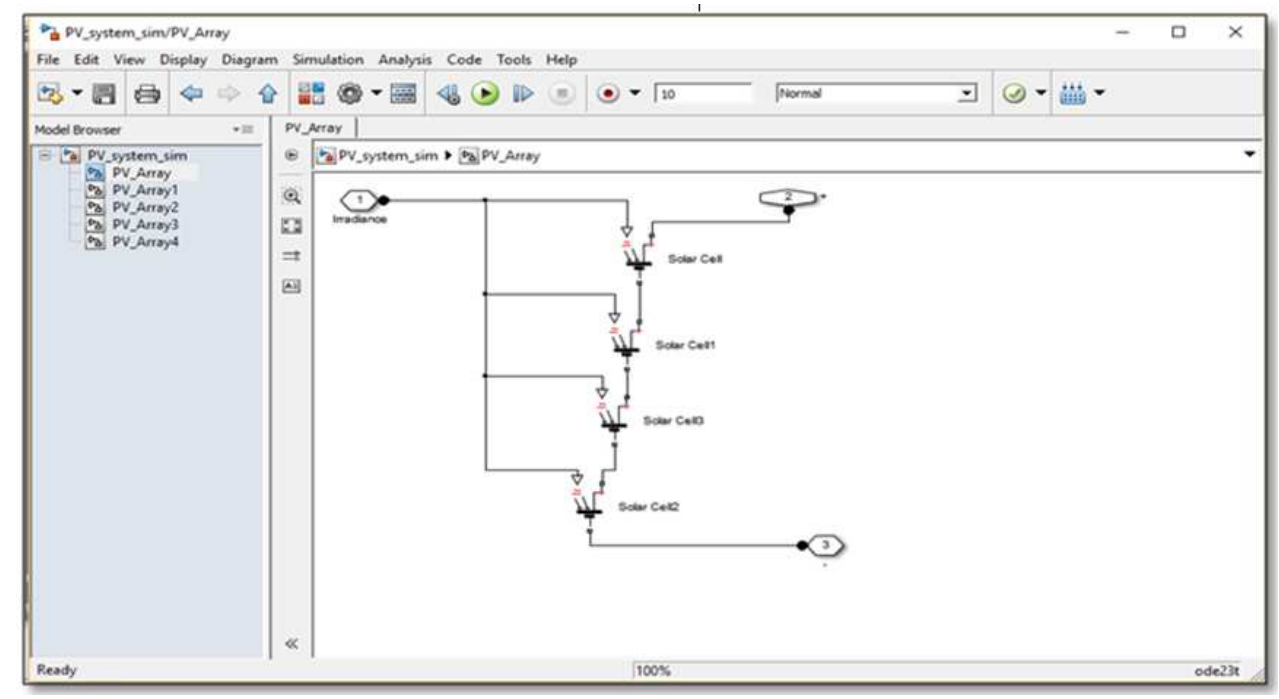

Fig. 3. Series connected stack of solar cells (2.4 Voc) 


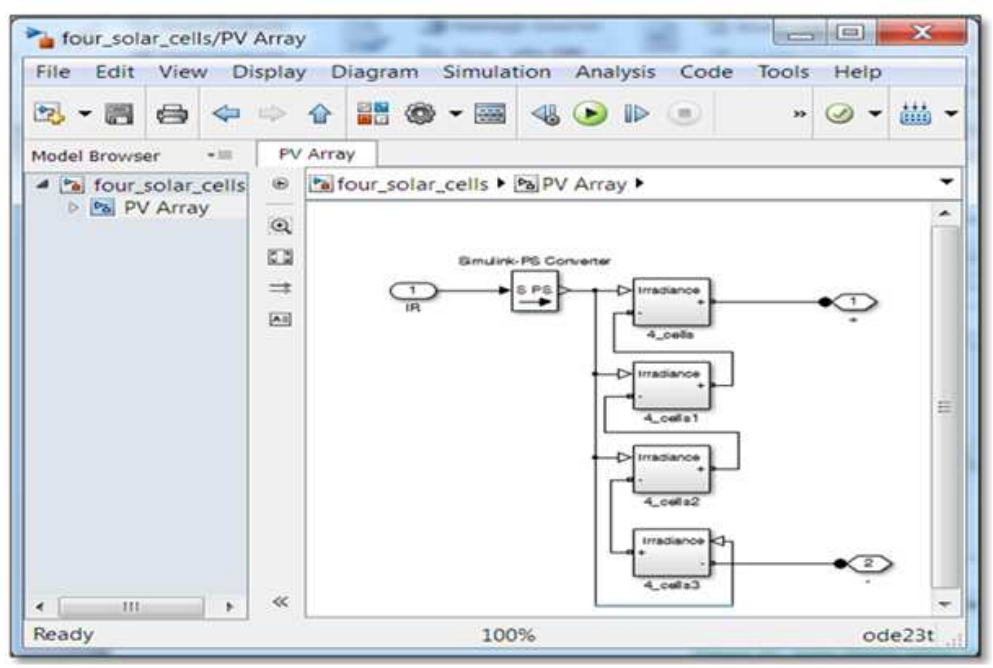

Fig. 4. PV Array collection

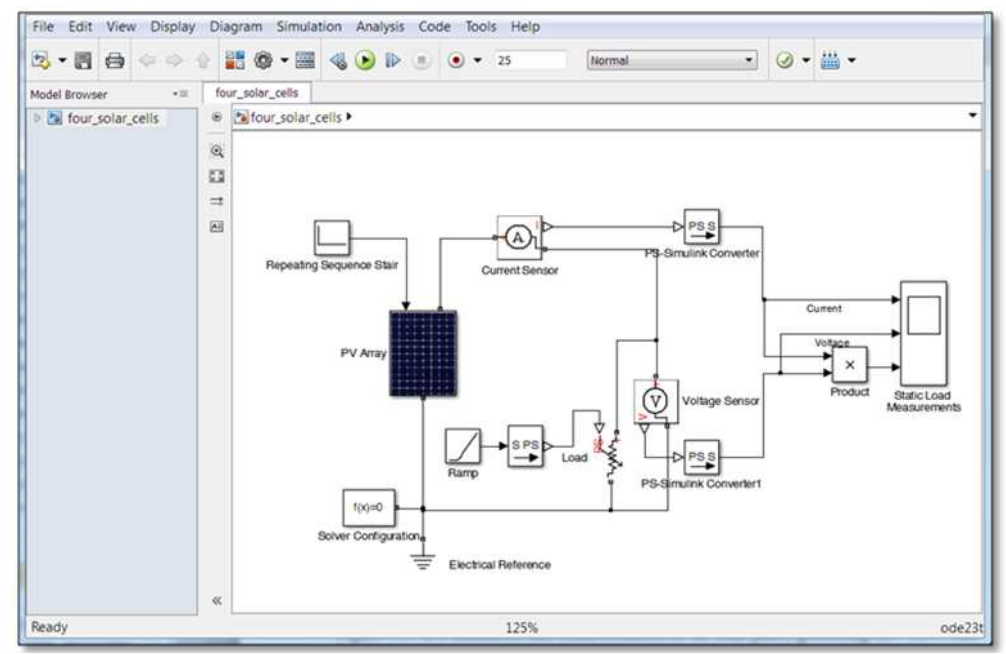

Fig. 5. Mobile Sensor Node Thin-film solar $\sim 5 \mathrm{~V}$

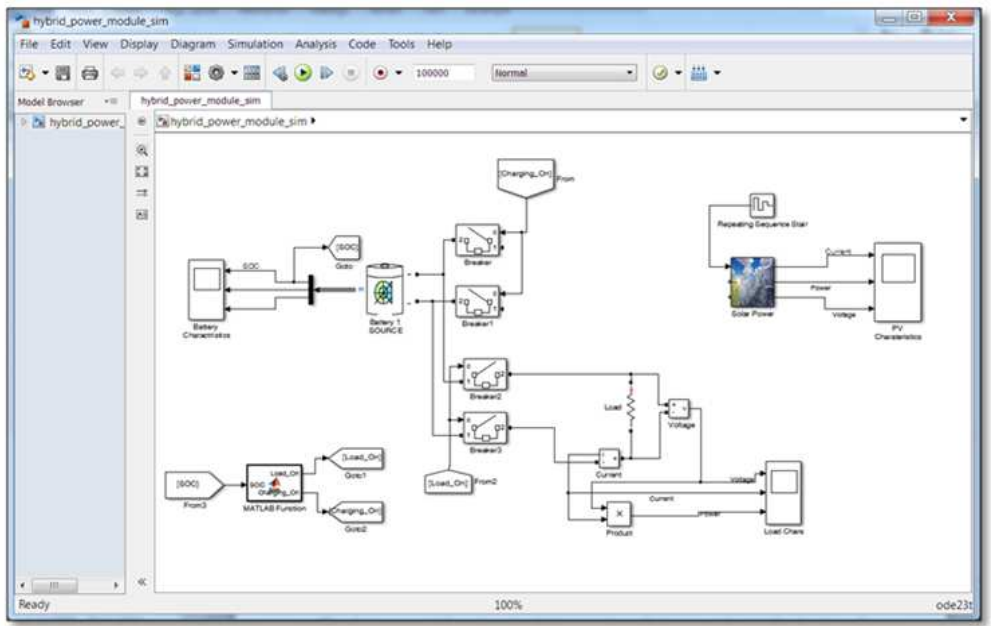

Fig. 6. Hybrid power system 
Figure 5 shows a model for the 4.8 Voc wearable thin film solar cell, the thin film solar cell array paired with Li-ion batteries form the hybrid power module. The variable resistor connected in parallel to the voltage sensor represents the load i.e. the ear tag device.

Figure 5 also depicts the $12 \mathrm{~V}$ open circuit voltage solar panel model which is made up of series connected PV array blocks shown in Fig. 3 and Fig. 4.

\section{Hybrid Power Module}

The hybrid power module comprises of Li-ion batteries and thin film solar cells for the mobile sensor power (ear tag), and NimH batteries and solar panel for static sensor power. This hybrid system also includes a switching mechanism to select between the combined power modules. Switching between the two power modules is done through breakers, when power generated by any running module reach a limit of $40 \%$ or $80 \%$ State of Charge (SOC). The breaker switches and allows the device to be powered from the other power module, while the other power module is being recharged.

Assuming a $1000 \mathrm{~mA} / \mathrm{h}$ supply of solar irradiance, the solar power module sub-system block is connected to complete hybrid power system as shown in Fig. 6. The load represents either the mobile sensor nodes (ear tags) or static sensor nodes. The power switching module uses the flags or go-to tags to connect the circuits using breakers.

\section{Results}

This section presents the power simulation results for the mobile sensor battery (Li-ion), static sensor battery $(\mathrm{NimH})$, ear tag (thin film solar cells), solar panels and the hybrid power module.

\section{Mobile Sensor Node Battery (Li-ion)}

Figure 7 and Fig. 8 respectively show the expected discharge characteristics and the simulated output for a $5 \mathrm{~mA}$ load..

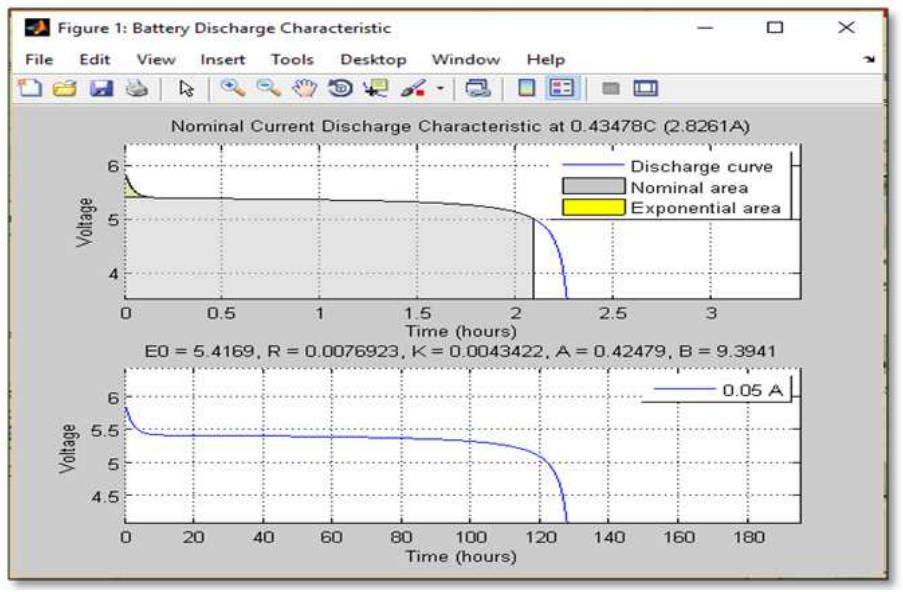

Fig. 7. Li-ion (5V) expected discharge characteristics for a 5mA Load (Gow and Manning, 1999)

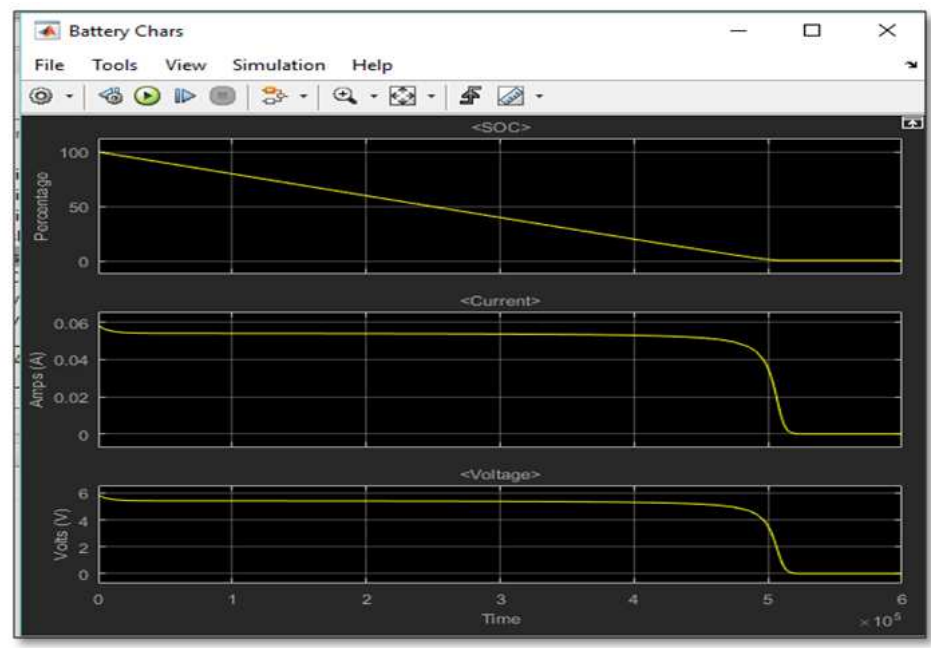

Fig. 8. Li-ion $5 \mathrm{~V}$ simulation output for a $5 \mathrm{~mA}$ Load 


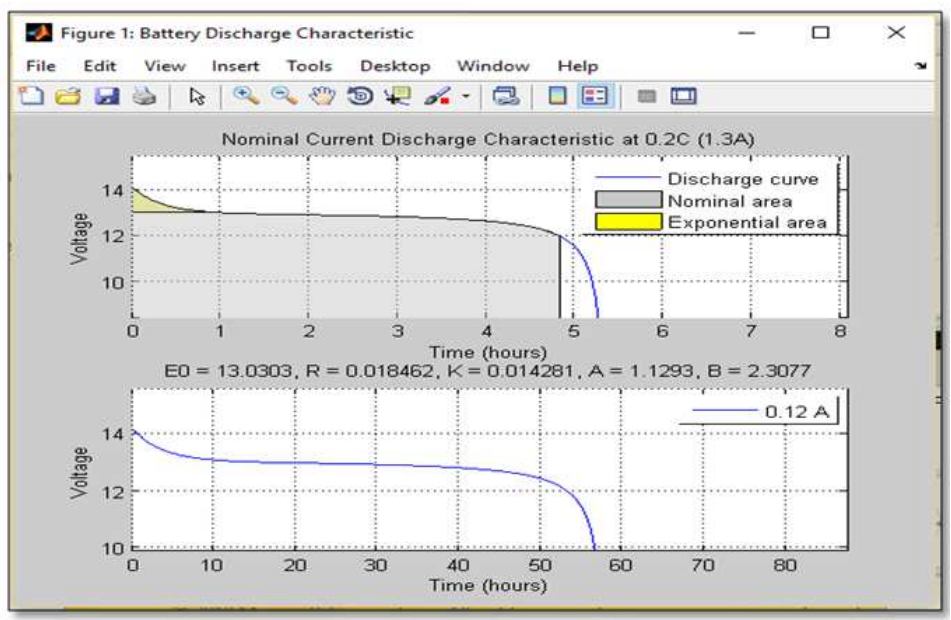

Fig. 9. NimH $12 \mathrm{~V}$ expected discharge characteristics (Gow and Manning, 1999)

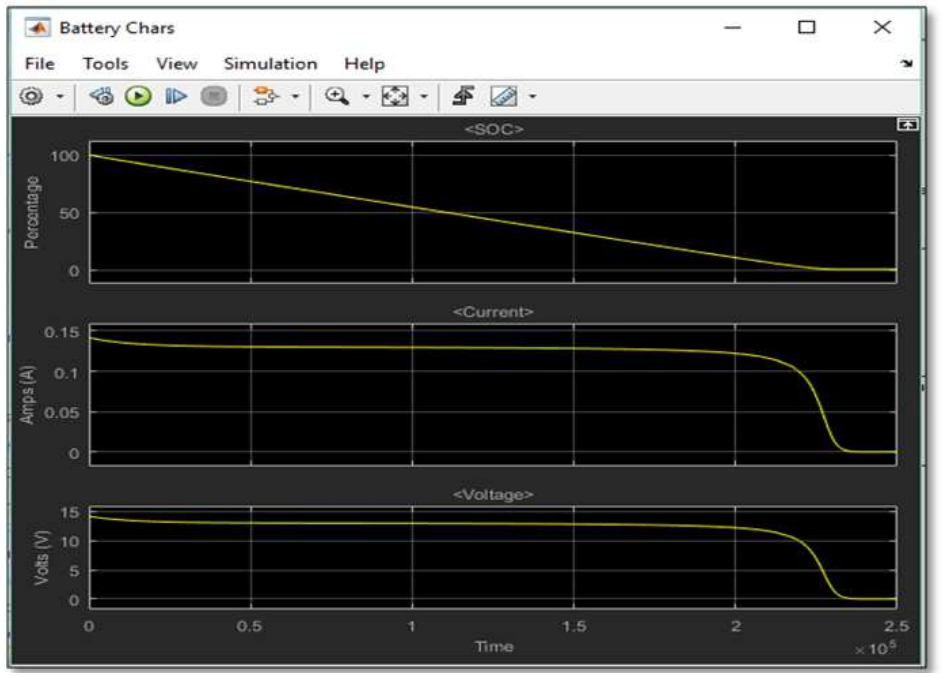

Fig.10. NimH $12 \mathrm{~V}$ battery simulation output

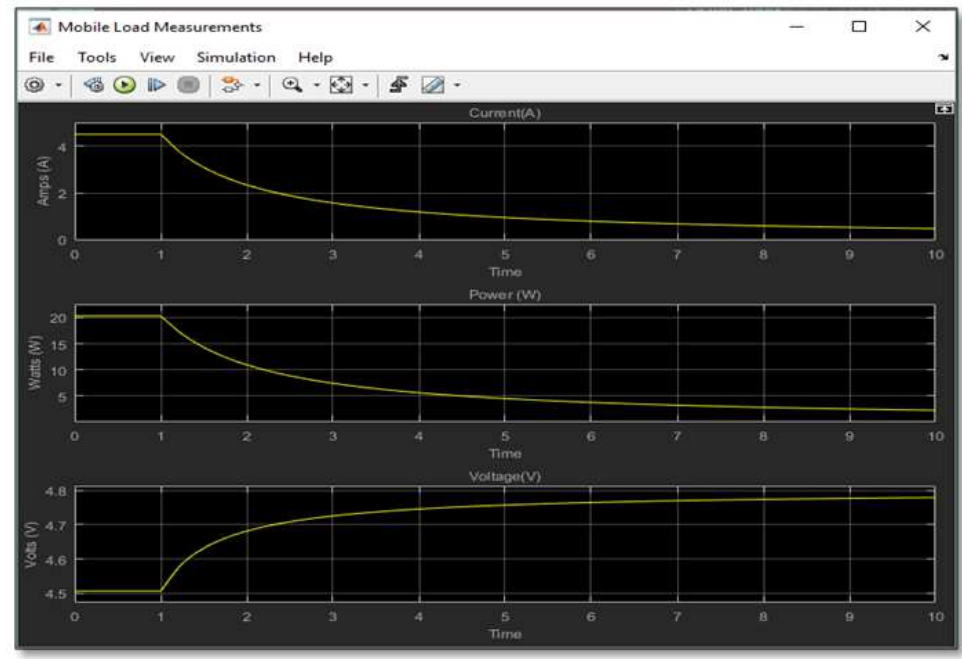

Fig. 11. Thin-film solar cel characteristics $\sim 5 \mathrm{~V}$ 


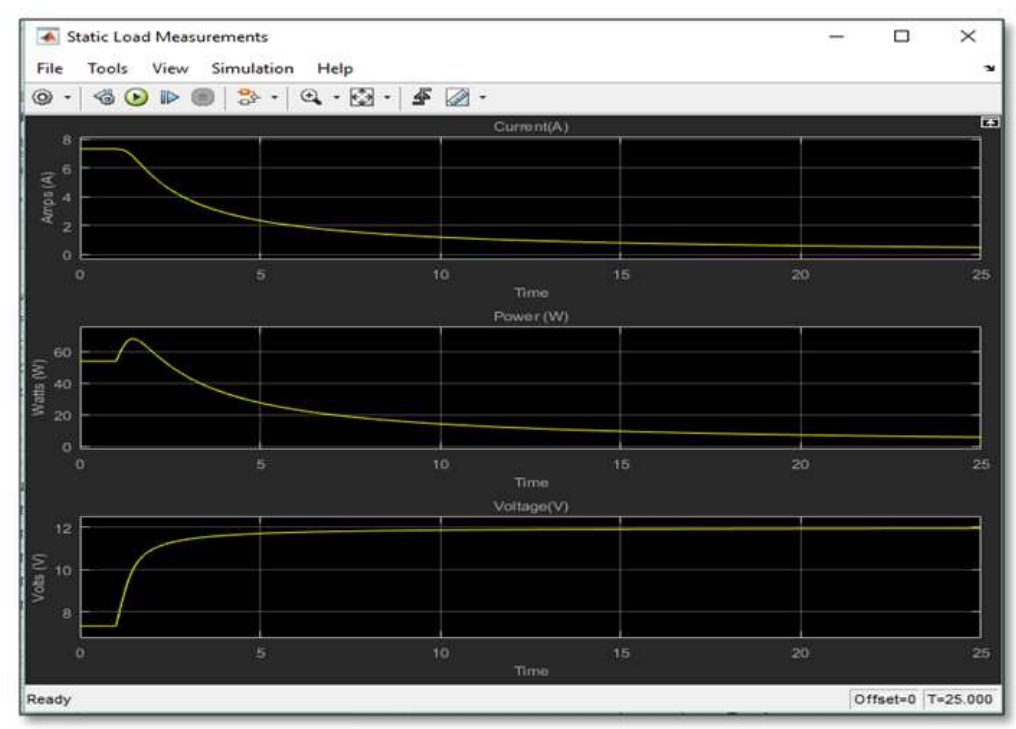

Fig. 12. Solar panel simulation output 12 Voc

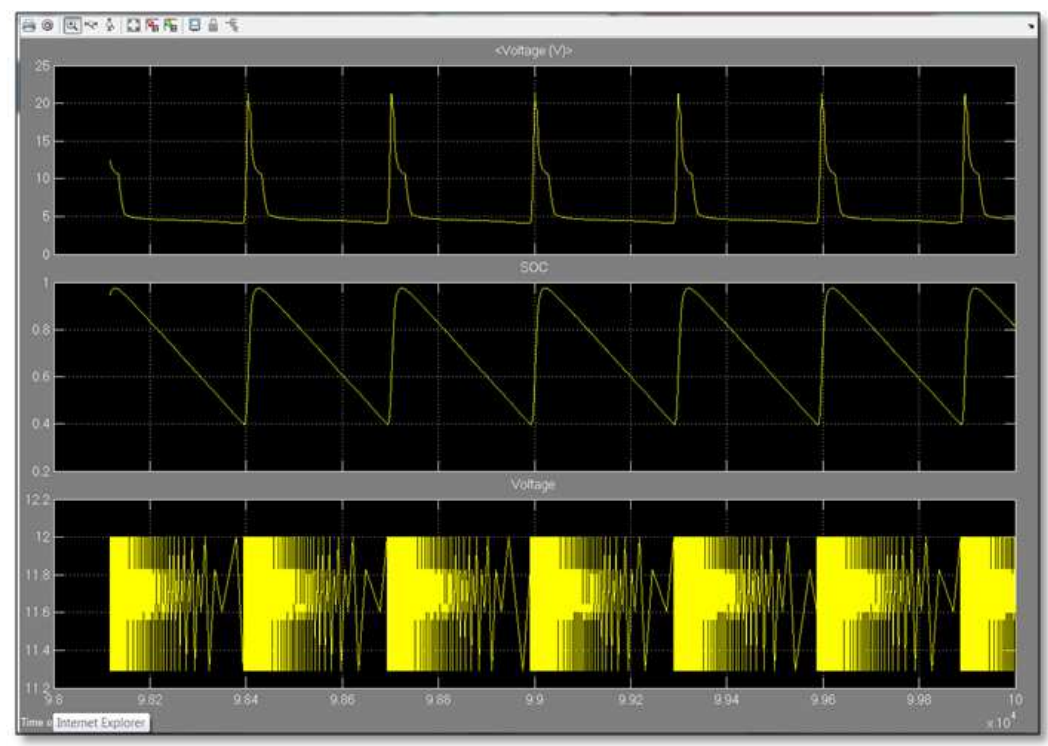

Fig.13. Hybrid power system simulation output

\section{Static Sensor Node Battery (NimH)}

Figure 9 and Fig. 10 show the expected characteristics of a NimH battery and the simulation output for a $1.48 \mathrm{~mA}$ load respectively.

\section{Thin Film Solar Cell and Solar Panel}

Figure 11 respectively show the simulation results for a $5 \mathrm{~V}$ thin-film solar cell and a solar panel producing $12 \mathrm{Voc}$ from 5 solar arrays of 4 solar cells.

\section{Hybrid Power System}

Figure 12 shows the simulation output for the hybrid power system

\section{Discussion}

As shown in Fig. 8, a current of $0.05 \mathrm{~A}$ is discharged from the mobile sensor node (ear tag); its power last for about 116 hours. When a load of 100 ohms and a $5 \mathrm{~V}$ nominal voltage is used; the power module provides around 117 hours or about 5 days of power to the ear tag.

Under a load of $1.48 \mathrm{~mA}$, NimH battery results in a nominal area of about 51 hours Fig. 9 and Fig. 10. When a load of $100 \mathrm{ohm}$ is connected drawing $12 \mathrm{~mA}$ current, NimH battery lasts for about 50 hours implying two days' worth of power before recharging. 
The solar cell generates 4.8 Voc necessary to power the mobile sensor node Fig. 11. The delay in the signal is as a result of the ramp required to generate varying resistance for the solar cell array. The solar cell generates a DC voltage while power follows the declining current curve. A $12 \mathrm{Voc}, 70 \mathrm{~W}$ solar panel generates a DC voltage that is used to charge the battery and to also power a load Fig. 12. Results for the hybrid system Fig. 13 indicate that when the primary power source (battery) is discharging, the SOC decreases. When the secondary power source (solar panel) is powering the load and also charging the primary source, the SOC increases. The SOC switches power sources at $40 \%$ because a battery generates a working power up to until $40 \%$ SOC. To maintain a normal working system, the nominal area should not be surpassed. The solar system produces enough power to charge the battery during the operation of the hybrid system.

\section{Conclusion}

This paper describes the development of a hybrid power module for wireless sensor networks (WSN) to be utilised in a livestock tracking and identification system. Mathematical and MATLAB-Simulink models are developed and used to simulate the characteristics of a lithium ion (Li-ion) battery-used to power the mobile sensor node (eartag), a nickel metal hydrate (NimH) battery used to power the static sensor nodes, a solar cell and the hybrid power module which comprises off Li-ion batteries and solar cells.

Simulation results shows that the Li-ion battery generates about five (5) days of power to the ear tag, the NimH battery lasts for about two (2) days before recharging is necessary. The solar cell alone generates 4.8 Voc necessary to power the mobile sensor node. A $12 \mathrm{Voc}, 70 \mathrm{~W}$ solar panel generates a DC voltage necessary to charge the battery while powering a load at the same time. Individually, the power sources provide limited power but the hybrid system coupled with a switching block generates enough power for the system, this implies that the system is viable. A prolonged operation of the system will depend on the battery limitations and climatic conditions.

\section{Further Study}

Future work will focus on the development of a prototype. The prototype will also be tested and validated in real environment.

\section{Acknowledgement}

We express our appreciation to Dr. M.A Zungeru for his advice and to the Botswana International University of Science and Technology's for sponsoring this research work.

\section{Author's Contributions}

Mr Maphane: Participated in the conceptualisation of the research, collectionof data, modelling \&simulation, analysis \& interpretaion of the results, drafting \& reviewing of the manuscript. He approves this version of the document to be submitted.

Dr. Matsebe: Is the supervisor and coordinator of the research. He participated in the conceptualisation, coordination and designing of the research,contributed to the the analysis \& interpretation of results. He also drafted \& reviewed the manuscript. He approves this version of the manuscript to be submitted.

Dr. Namosheis: Is the co-supervisor of the research. He participated in the conceptualisation and designing of the research,contributed to the analysis \& interpretation of results. He also reviewed the manuscript. He approves this version of the manuscript to be submitted.

\section{Ethics}

This article is original and contains unpublished material. The corresponding author confirms that all of the other authors have read and approved the manuscript and there are no ethical issues involved.

\section{References}

Choi, S.G., E. Norinpel and J. Yoo, 2013. Cluster-based routing protocol in wireless sensor networks for tracking livestock movements in Mongolian nomadic herding. Jun. 28-Jul. 1, IEEE Xplore Press, Ulaanbaatar, Mongolia, pp: 163-167. DOI: 10.1109/IFOST.2

Foulkes, J., P. Tucker and M. Caronan, 2013. Livestock management system. Proceedings of the International Conference on Embedded Systems and Applications, (ESA' 13), Athens: pp: 1-7.

Gow, J.A. and C.D. Manning, 1999. Development of a photovoltaic array model for use in powerelectronics simulation studies. IEEE Proc. Electr. Power Applic., 146: 193-200. DOI: 10.1049/ipepa:19990116

Huircan, J.I., C. Muñoz, H. Young, L.V. Dossow and J. Bustos et al., 2010. ZigBee-based wireless sensor network localization for cattle monitoring in grazing fields. Comput. Electr. Agric., 74: 258-264.

DOI: 10.1016/j.compag.2010.08.014

Jager, K., O. Isabella, M. Zeman and R. van Swaaij, 2014. Solar energy fundamentals, technology and systems. Delft.

Kwong, K.H., K. Sasloglou, H.G. Goh, T.T. Wu and B. Stephen et al., 2009. Adaptation of wireless sensor network for farming industries. Proceedings of the 6th International Conference on Networked Sensing Systems, Jun. 17-19, IEEE Xplore Press, Pittsburgh. 
Kwong, K.H., T.T. Wu, H.G. Goh, K. Sasloglou and B. Stephen et al., 2012. Practical considerations for wireless sensor networks in cattle monitoring applications. Comput. Electr. Agric., 81: 33-44. DOI: 10.1016/j.compag.2011.10.013

Nagl, L., R. Schmitz, S. Warren, T.S. Hildreth and H. Erickson et al., 2003. Wearable sensor system for wireless state-of-health determination in cattle. Proceedings of the 25th Annual International Conference of the IEEE Engineering in Medicine and Biology Society, Sept. 17-21, IEEE Xplore Press, Cancun, Mexico, pp: 3012-3015.

DOI: $10.1109 /$ IEMBS.2003.1280774
Raizma, E.A., H.B. Rasmussen, L.E. King, F.W. Ih and I. Douglas-Hamilton et al., 2013. Feasibility study on the spatial and temporal movement of Samburu Cattle and wildlife in Kenya Using GPS radio tracking, remote sensing and GIS. Preventive Vet. Med.. 111: 76-80.

DOI: 10.1016/j.prevetmed.2013.04.007

Tremblay, O. and L.A. Dessaint, 2009. Experimental Validation of a Battery Dynamic Model for EV Applications. World Electric Vehicle, 3: 289-298. 